\title{
A Physical Mechanism for Suppression of Zinc Dendrites Caused by High Efficiency of the Electrodeposition within Confined Nanopores
}

\section{AUTHOR(S):}

Koda, Ryo; Fukami, Kazuhiro; Sakka, Tetsuo; Ogata, Yukio $\mathrm{H}$.

\section{CITATION:}

Koda, Ryo .... [et al]. A Physical Mechanism for Suppression of Zinc Dendrites Caused by High Efficiency of the Electrodeposition within Confined Nanopores. ECS

electrochemistry letters 2012, 2(2): D9-D11

\section{ISSUE DATE:}

2012-11-30

URL:

http://hdl.handle.net/2433/193700

\section{RIGHT:}

(c) The Electrochemical Society, Inc. 2012. All rights reserved. Except as provided under U.S. copyright law, this work may not be reproduced, resold, distributed, or modified without the express permission of The Electrochemical Society (ECS). 


\title{
(4) \\ A Physical Mechanism for Suppression of Zinc Dendrites Caused by High Efficiency of the Electrodeposition within Confined Nanopores
}

\author{
Ryo Koda, Kazuhiro Fukami, ${ }^{*, z}$ Tetsuo Sakka, ${ }^{*, a}$ and Yukio H. Ogata* \\ Institute of Advanced Energy, Kyoto University, Uji, Kyoto 611-0011, Japan
}

\begin{abstract}
A strategy for the suppression of zinc dendrites in electrodeposition controlled by a physical factor has been proposed and demonstrated. Zinc electrodeposition within confined nanopores shows a high current efficiency even at a current density higher than the diffusion-limited current measured on a planar substrate. Our results suggest that the electrodeposition is free from the diffusionlimitation problem only when the electrodeposition occurs within the confined nanopores. (C) 2012 The Electrochemical Society. [DOI: 10.1149/2.010302eel] All rights reserved.
\end{abstract}

Manuscript submitted October 19, 2012; revised manuscript received November 16, 2012. Published November 30, 2012.

Dendrite growth in metal electrodeposition is a typical reactiondiffusion system whose dynamics is described by differential equations of positive and negative feedback species. ${ }^{1-5}$ Since diffusion of metal ions plays a significant role in dendrite formation, understanding of mass-transfer during metal electrodeposition is important. From an electrochemical viewpoint, dendrite growth is crucially important and must be suppressed in the development of rechargeable batteries. Strategies to suppress such dendrites have been proposed and demonstrated. ${ }^{6-8}$ A problem in these strategies was that the suppression was controlled by chemical factors such as additives and surfactants. Effective additives and surfactants differ depending upon the types of metal depositions. A general strategy for the suppression of dendrites by physical factors, which is applicable to any metal electrodes, is urgently desired.

Recently, we have reported that the electrochemical deposition was drastically accelerated when using hydrophobic porous silicon, while it was surprisingly decelerated when using hydrophilic one. ${ }^{9}$ Such a substantial difference within confined nanopores is due to the fact that metal ions having a large diameter behave as hydrophobic solutes and tend to be excluded from the bulk to the hydrophobic pore wall. This exclusion of metal ions (a physical factor) results in a great enrichment of the ions in the confined nanopores. This enrichment leads to the idea that diffusion-limited electrodeposition, in which dendrites grow, is hard to be achieved within confined and hydrophobic nanopores.

In this letter, we report that growth of zinc dendrites is suppressed by the physical factor (exclusion of zinc toward hydrophobic nanopore walls) using porous silicon whose pore size is $\sim 3 \mathrm{~nm}$. The present study is fundamentally of great importance for the suppression of dendrites caused by a physical factor.

\section{Experimental}

Porous silicon, whose pore diameter was $\sim 3 \mathrm{~nm}$ and thickness was $2 \mu \mathrm{m}$, was prepared by anodization. An n-type silicon (100) substrate with a resistivity of 7-20 $\Omega \mathrm{cm}$ was used. As shown later, the porous silicon looks like a macropore structure, which is so-called skeleton and completely filled with a microporous silicon body. ${ }^{10}$ A mixture of $22 \mathrm{wt} \% \mathrm{HF} / \mathrm{ethanol}$ was used as electrolyte solution. Anodization was carried out for $20 \mathrm{~min}$ at $2 \mathrm{~mA} \mathrm{~cm} \mathrm{~cm}^{-2}$ under illumination. In some experiments, a thicker porous silicon with $3 \mu \mathrm{m}$ was used. The thicker porous silicon was prepared by anodization for $30 \mathrm{~min}$.

Zinc electrodeposition was carried out under the galvanostatic mode. A zinc plate, flat silicon and porous silicon were used as the working electrode for comparison. The zinc plate was polished with alumina powders $(3 \mu \mathrm{m}$ and $0.3 \mu \mathrm{m})$. The counter and reference electrodes were a platinum rod and $\mathrm{Agl} \mathrm{AgCl}$ saturated $\mathrm{KCl}$ electrodes, respectively. All the potentials shown in the present paper are referred

*Electrochemical Society Active Member

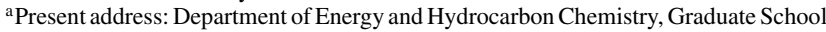
of Engineering, Kyoto University, Kyoto 615-8510, Japan

${ }^{\mathrm{z}}$ E-mail: fukami.kazuhiro.2u@kyoto-u.ac.jp to this electrode. $0.1 \mathrm{M} \mathrm{ZnSO}_{4}+0.5 \mathrm{M} \mathrm{Na}_{2} \mathrm{SO}_{4}$ aqueous solution, whose $\mathrm{pH}$ was adjusted to 4.0 by adding a small amount of $\mathrm{H}_{2} \mathrm{SO}_{4}$, was used as deposition bath. When measuring current density vs. potential $(i-E)$ curves, potential was scanned at a rate of $10 \mathrm{mV} \mathrm{s}^{-1}$.

Surfaces and cross-sections of the specimen were observed using a scanning electron microscope (SEM). To measure current efficiency on the planar silicon wafer and porous silicon, deposited zinc was dissolved by immersing the substrate in a dilute $\mathrm{HNO}_{3}$. This solution was diluted with ultra-pure water and the concentration of zinc ions in the dilute solution was measured using an inductively coupled plasma atomic emission spectrometer (ICP).

\section{Results and Discussion}

An $i-E$ curve using a zinc plate was measured to determine the diffusion-limited current density $\left(i_{\text {diff }}\right)$. Potential scan was started at $-1.0 \mathrm{~V}$ to negative. A cathodic current due to zinc electrodeposition starts to flow at $-1.1 \mathrm{~V}$ and it reaches a plateau at $-9 \mathrm{~mA} \mathrm{~cm}^{-2}$. Such an $i-E$ curve is also obtained on a flat silicon wafer. These results show that the $i_{\text {diff }}$ in this electrolyte condition is $\sim-9 \mathrm{~mA} \mathrm{~cm}^{-2}$. The broken line shows an $i-E$ curve on porous silicon. The behavior looks similar to the others, except that the cathodic current in high overpotential region starts to flow at a higher potential $(-1.6 \mathrm{~V})$. Figures $1 \mathrm{~b}$ and 1c show SEM images of zinc deposits on the zinc plates formed at $-6.4 \mathrm{~mA} \mathrm{~cm}{ }^{-2}\left(|i|<\left|i_{\text {diff }}\right|\right)$ and $-12.8 \mathrm{~mA} \mathrm{~cm}{ }^{-2}$ ( $\left.|i|>\left|i_{\text {diff }}\right|\right)$. Zinc deposited under $|i|<\left|i_{\text {diff }}\right|$ shows a flat and compact structure, whereas zinc dendrites are observed under $|i|>\left|i_{\text {diff }}\right|$.

A zinc plate, flat silicon wafer and porous silicon were used to investigate the effect of substrates on the dendrite growth. Zinc electrodeposition was carried out for $30 \mathrm{~s}$ on each electrode at a cathodic current density of $-12.8 \mathrm{~mA} \mathrm{~cm}{ }^{-2}\left(|i|>\left|i_{\text {diff }}\right|\right)$. Figures $2 \mathrm{a}, 2 \mathrm{~b}$ and $2 \mathrm{c}$ show surface morphologies of zinc deposited on the electrodes. There are no significant differences between the zinc plate and flat silicon wafer. Zinc dendrites of height up to several micrometers are observed on the surfaces. By contrast, no dendrites are formed on the surface of porous silicon, but hexagonal crystals are observed. From the cross-sectional view (Figure 2e), zinc deposits are observed within the porous layer. The potential development in Figure $2 \mathrm{~g}$ on the zinc plate shows that a sudden shift in potential after $7 \mathrm{~s}$ of deposition, and then the potential reaches $-1.8 \mathrm{~V}$ (hydrogen evolution). When the flat silicon wafer is used, the development shows very similar trend as on the zinc plate electrode. The sudden shift in potential on the porous silicon occurs a little bit later. This delay suggests that it takes longer to consume zinc ions and to shift to hydrogen evolution when using the porous electrode. A thicker porous silicon was also used for the comparison. SEM images in Figures $2 \mathrm{~d}$ and $2 \mathrm{f}$ show that zinc dendrites are suppressed and the amount of the hexagonal deposits on the top surface is smaller than the thinner porous silicon (Figures $2 \mathrm{c}$ and $2 \mathrm{~d})$. The potential shift shows the delay of ten seconds from that of the shallow porous silicon, and the shift in potential with the thicker porous silicon is much gentler. Note that the effect of displacement 


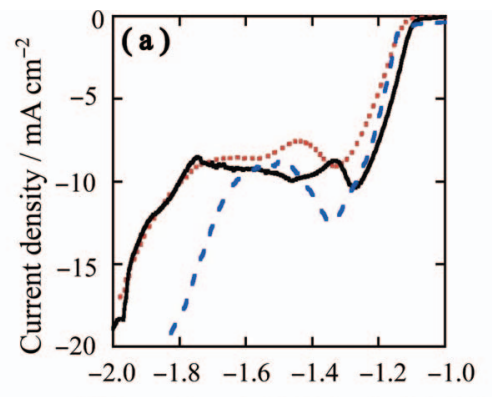

Potential vs. $\mathrm{Ag} \mid \mathrm{AgCl}$ sat. $\mathrm{KCl} / \mathrm{V}$
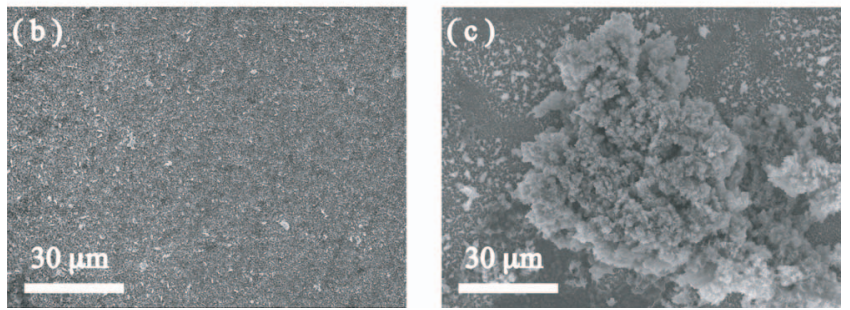

Figure 1. (a) Current density vs. potential curves measured on a zinc plate (black and solid curve), flat silicon wafer (red and dotted curve) and porous silicon (blue and broken curve) at a scan rate of $10 \mathrm{mV} \mathrm{s}^{-1}$ in $0.1 \mathrm{M} \mathrm{ZnSO}_{4}$ $+0.5 \mathrm{M} \mathrm{Na}_{2} \mathrm{SO}_{4}$ aqueous solution. Images in $(\mathrm{b}, \mathrm{c})$ show the surface after zinc electrodeposition on zinc plates at $-6.4 \mathrm{~mA} \mathrm{~cm}-2$ for 2 min and at $-12.8 \mathrm{~mA} \mathrm{~cm}^{-2}$ for $1 \mathrm{~min}$.

deposition was evaluated prior to the electrodeposition experiments, and we found that the contribution of displacement deposition to the increase in the electrode weight is very low $(0.9 \%)$. We have confirmed that no nucleation and growth of zinc within the pores were observed in the present case. In addition, the $i-E$ curve measured on porous silicon shows relatively similar to the others in low overpotential region $(-1.1 \mathrm{~V}$ to $-1.3 \mathrm{~V})$. Therefore, chemical contribution to the electrodeposition seems to be very small. Zinc electrodeposition within the nanopores cannot be explained by simply considering chemical effects such as the reactivity of hydrogen-terminated porous silicon.

Figure 3 shows current efficiencies measured on the flat and porous silicon. For $5 \mathrm{~s}$ of deposition, both the flat and porous silicon show high efficiencies. Since $|i|>\left|i_{\text {diff }}\right|$, the potential shift occurs after $7 \mathrm{~s}$ of deposition on the flat silicon as observed in Figure $2 \mathrm{~g}$. After this potential shift, the efficiency starts to decrease on the flat silicon. By contrast, the current efficiency on the porous silicon stays higher than that on the flat silicon. The difference in current efficiency between these electrodes becomes remarkable with prolonging the deposition time. As observed in Figure $2 \mathrm{~g}$, the potential shift is observed after $12 \mathrm{~s}$ of deposition (green curve). The efficiency measured on the porous silicon decreases after the potential shift. In Figure $2 \mathrm{~g}$, the potential shift is delayed from $12 \mathrm{~s}$ to $20 \mathrm{~s}$ when the thickness of the porous layer is changed from $2 \mu \mathrm{m}$ to $3 \mu \mathrm{m}$. We think that this delay in the potential shift is simply due to the increase in the volume for the filling with zinc deposits.

Metal dendrites grow under diffusion-limited condition. This means that the suppression of dendrites in electrodeposition conflicts with the deposition at $|i|>\left|i_{\text {diff }}\right|$. This is only the case that the supply of metal ions is described by the diffusion equation. If supply of metal ions is achieved by another process, there exists a possibility to suppress them. The effect of hydration property of pore wall has been investigated in detail by modifying porous silicon with two different organic molecules to make the porous silicon hydrophobic and hydrophilic. ${ }^{9}$ We found that platinum electrodeposition within confined nanopores shows a drastic acceleration of the deposition when using the hydrophobic nanopores and larger platinum ions. In principle, smaller pore diameter results in an inhibition of diffusion, which leads to a low efficiency of reactions in nanopores. Our theoretical analyses revealed that the surface-induced hydration structure in con-
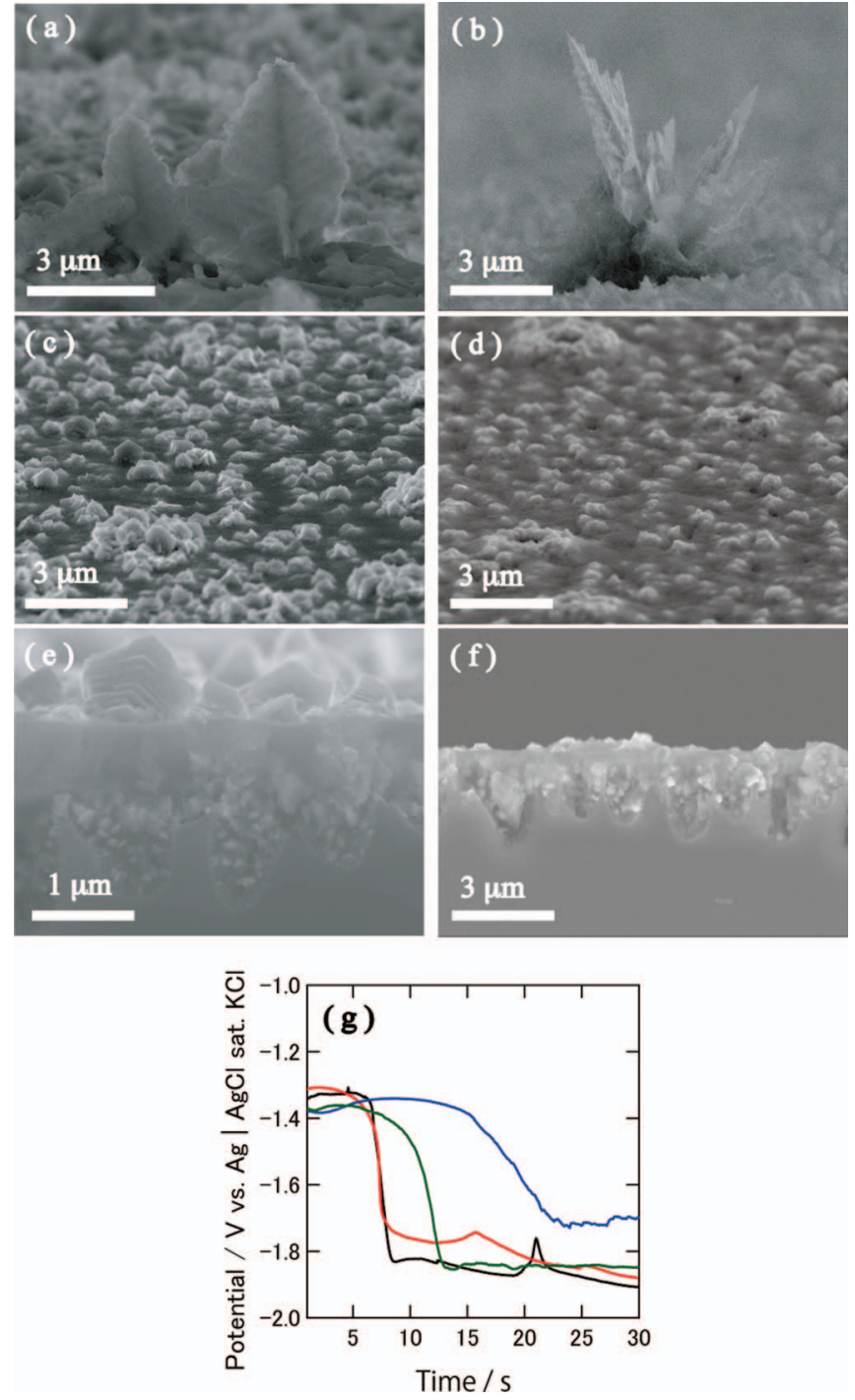

Figure 2. Images in $(a, b, c, d)$ show the surfaces after the electrodeposition on a zinc plate (a), flat silicon wafer (b), shallower porous silicon with $2 \mu \mathrm{m}$ depth (c) and deeper porous silicon with $3 \mu \mathrm{m}$ depth (d). The images in (e, f) show cross-sectional views of the samples shown in (c, d). Time developments in potential using the substrates are shown in (g). Curves in black, red, green and blue indicate the results measured on the zinc plate, flat silicon, shallower porous silicon and deeper porous silicon, respectively.

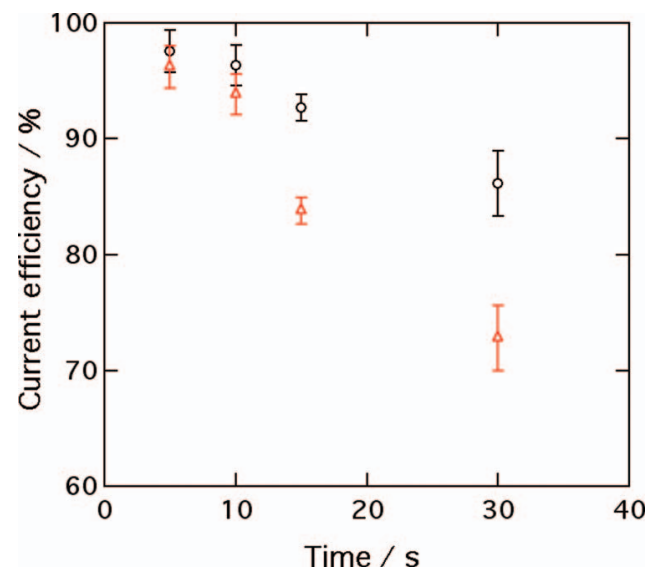

Figure 3. Current efficiencies measured after the electrodeposition on a flat silicon (red) and porous silicon (black). 
fined nanopores plays a significant role for the great enrichment of metal ions in the nanopores, leading to a high efficiency of metal electrodeposition. ${ }^{9}$ Note that such enrichment is expected only when using pores with several nanometers in diameter. Electrodeposition within mesoporous silicon ( $\sim 30 \mathrm{~nm}$ in diameter $)$ did not show such a drastic acceleration of the deposition. ${ }^{11}$ Judging from Figure $2 \mathrm{e}$ and $2 \mathrm{f}$, complete filling of the porous silicon with zinc has not been achieved so far. We think that further tuning of the surface-induced hydration structure by the affinities of zinc ion and pore wall with water will result in higher density of zinc deposits within the nanopores. The high concentration in confined nanopores, which is the origin of the high current efficiency in the present system and suppression of dendrites, is achieved not by diffusion but by the other physical factor (exclusion of zinc ions to the hydrophobic pore wall).

\section{Conclusions}

Due to the fact that a higher concentration of zinc ions is expected in the hydrophobic nanopores, zinc dendrites are suppressed even at $|i|>\left|i_{\text {diff }}\right|$ when the electrodeposition primarily occurs within the confined nanopores. The present study is fundamentally important for further development of rechargeable batteries without the dendrite problem.

\section{Acknowledgments}

R.K. expresses his thanks for the Global COE program, "Energy Science in the Age of Global Warming." This work is supported by a JSPS grant-in-Aid for Young Scientists (B) (grant no. 23750239).

\section{References}

1. S. Nakanishi, K. Fukami, T. Tada, and Y. Nakato, J. Am. Chem. Soc., 126, 9556 (2004).

2. K. Fukami, S. Nakanishi, T. Tada, H. Yamasaki, S. I. Sakai, S. Fukushima, and Y. Nakato, J. Electrochem. Soc., 152, C493 (2005).

3. K. Fukami, S. Nakanishi, H. Yamasaki, T. Tada, K. Sonoda, N. Kamikawa, N. Tsuji, H. Sakaguchi, and Y. Nakato, J. Phys. Chem C, 111, 1150 (2007).

4. M. Matsushita, M. Sano, Y. Hayakawa, H. Honjo, and Y. Sawada, Phys. Rev. Lett., 53, 286 (1984).

5. W. W. Mullins and R. F. Sekerka, J. Appl. Phys., 34, 323 (1963).

6. F. Mansfeld and S. Gilman, J. Electrochem. Soc., 117, 1154 (1970).

7. J. L. Zhu, Y. H. Zhou, and C. Q. Gao, J. Power Sources, 72, 231 (1998)

8. H. Sano, H. Sakaebe, and H. Matsumoto, J. Electrochem. Soc., 158, A316 (2011).

9. K. Fukami, R. Koda, T. Sakka, T. Urata, K. Amano, H. Takaya, M. Nakamura, Y. Ogata, and M. Kinoshita, Chem. Phys. Lett., 542, 99 (2012).

10. D. Hamm, T. Sakka, and Y. H. Ogata, Electrochemistry, 71, 853 (2003).

11. K. Fukami, Y. Tanaka, M. L. Chourou, T. Sakka, and Y. H. Ogata, Electrochim. Acta, 54, 2197 (2009) 